\title{
Estimation of Plutonium-240 Mass in Waste Tanks Using Ultra-Sensitive Detection of Radioactive Xenon Isotopes from Spontaneous Fission
}

\section{May 2017}

$\begin{array}{ll}\text { TW Bowyer } & \text { DP Mendoza } \\ \text { CJ Gesh } & \text { KB Olsen } \\ \text { DA Haas } & \text { AM Prinke } \\ \text { JC Hayes } & \text { BD Reid } \\ \text { JM Johns } & \text { GJ Sevigny } \\ \text { CD Lukins } & \text { SI Sinkov } \\ \text { LA Mahoney } & \text { VT Woods } \\ \text { JE Meacham } & \end{array}$




\title{
DISCLAIMER
}

This report was prepared as an account of work sponsored by an agency of the United States Government. Neither the United States Government nor any agency thereof, nor Battelle Memorial Institute, nor any of their employees, makes any warranty, express or implied, or assumes any legal liability or responsibility for the accuracy, completeness, or usefulness of any information, apparatus, product, or process disclosed, or represents that its use would not infringe privately owned rights. Reference herein to any specific commercial product, process, or service by trade name, trademark, manufacturer, or otherwise does not necessarily constitute or imply its endorsement, recommendation, or favoring by the United States Government or any agency thereof, or Battelle Memorial Institute. The views and opinions of authors expressed herein do not necessarily state or reflect those of the United States Government or any agency thereof.

\author{
PACIFIC NORTHWEST NATIONAL LABORATORY \\ operated by \\ BATTELLE \\ for the \\ UNITED STATES DEPARTMENT OF ENERGY \\ under Contract DE-AC05-76RL01830
}

Printed in the United States of America
Available to DOE and DOE contractors from the Office of Scientific and Technical Information,
P.O. Box 62, Oak Ridge, TN 37831-0062;
ph: (865) 576-8401
fax: $(865)$ 576-5728
email: reports@adonis.osti.gov

\begin{abstract}
Available to the public from the National Technical Information Service, U.S. Department of Commerce, 5285 Port Royal Rd., Springfield, VA 22161 ph: (800) 553-6847 fax: $(703) 605-6900$ email: orders@ntis.fedworld.gov online ordering: http://www.ntis.gov/ordering.htm
\end{abstract}

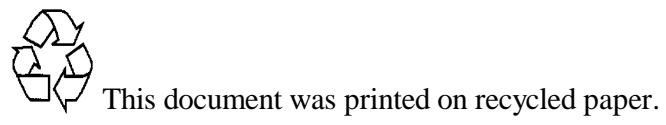




\section{Estimation of Plutonium-240 Mass in a Waste Tanks Using Ultra- Sensitive Detection of Radioactive Xenon Isotopes from Spontaneous Fission}

$\begin{array}{ll}\text { TW Bowyer } & \text { DP Mendoza } \\ \text { CJ Gesh } & \text { KB Olsen } \\ \text { DA Haas } & \text { AM Prinke } \\ \text { JC Hayes } & \text { BD Reid } \\ \text { JM Johns } & \text { GJ Sevigny } \\ \text { CD Lukins } & \text { SI Sinkov } \\ \text { LA Mahoney } & \text { VT Woods } \\ \text { JE Meacham } & \end{array}$

May 2017

Prepared for the U.S. Department of Energy under Contract DE-AC05-76RL01830

Pacific Northwest National Laboratory

Richland, Washington 99352 



\section{Abstract}

This report details efforts to develop a technique which is able to detect and quantify the mass of ${ }^{240} \mathrm{Pu}$ in waste storage tanks and other enclosed spaces. If the isotopic ratios of the plutonium contained in the enclosed space is also known, then this technique is capable of estimating the total mass of the plutonium without physical sample retrieval and radiochemical analysis of hazardous material. Results utilizing this technique are reported for a Hanford Site waste tank (TX-118) and a well-characterized plutonium sample in a laboratory environment. 


\section{Contents}

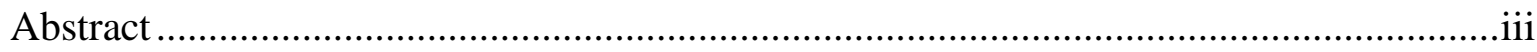

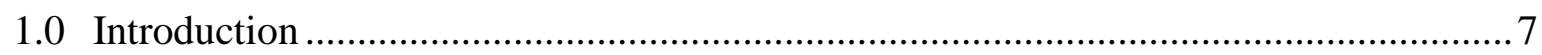

2.0 Gas Accumulation from Spontaneous Fission in Waste Tanks ................................. 7

2.1 Generation of Radioxenon by Spontaneous Fission........................................... 7

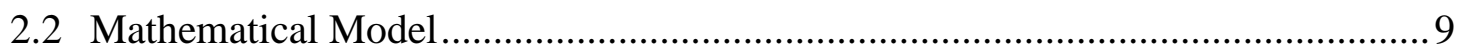

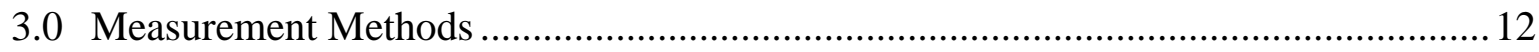

3.1 Swedish Automated Noble Gas Analysis System .......................................... 12

4.0 Waste Tank Sample Collection Procedure (Tank TX-118) .................................... 15

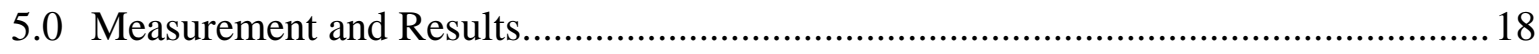

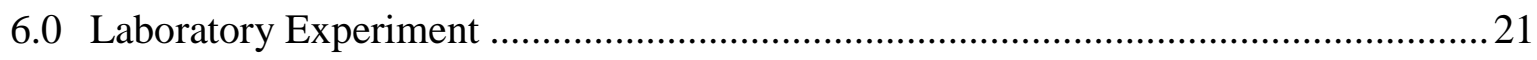

6.1 Experimental Setup and Sample Collection ................................................... 21

6.2 Laboratory Scale Experiment - Measurement and Results ...............................24

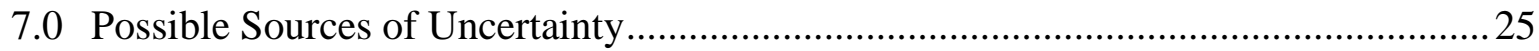

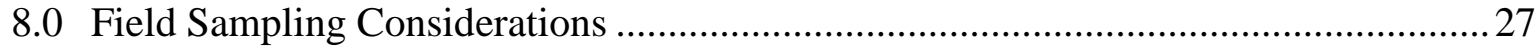

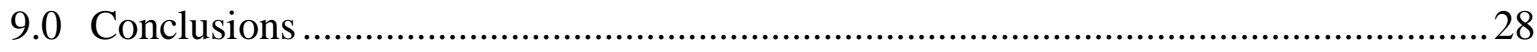

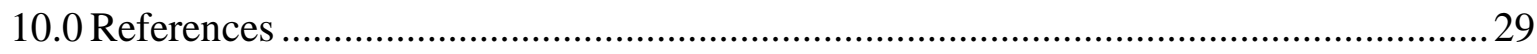




\section{Figures}

Figure 2-1: Theoretical cumulative mass yields for ${ }^{240} \mathrm{Pu}$ spontaneous fission................... 9

Figure 2-2: Schematic for calculation of flow into and out of tank, used for calculating the effect of dilution of radioxenon in the headspace of the waste tank. .................... 10

Figure 3-1: SAUNA-II System located at Pacific Northwest National Laboratory ............ 12

Figure 3-2: PNNL SAUNA-II sampling hardware schematic ...................................... 13

Figure 3-3: Modification to the SAUNA sampling system. A 3 way valve was introduced after the water separation unit. .................................................................... 14

Figure 4-1: Schematic of waste tank sampling. .......................................................... 16

Figure 4-2: Sampling trailer deployed at a sampling site. ........................................... 17

Figure 5-1: Beta spectrum in coincidence with the 30-keV x-ray peak of the one of the samples of headspace gas, clearly showing the expected conversion electron from ${ }^{131 \mathrm{~m}} \mathrm{Xe}$ on top of the beta continuum from ${ }^{133} \mathrm{Xe}$..................................................... 19

Figure 5-2: ${ }^{131 \mathrm{~m}} \mathrm{Xe} /{ }^{133} \mathrm{Xe}$ Activity Ratio as a Function of Venting Rate ............................ 20

Figure 6-1: Glove box sample collection setup ........................................................22

Figure 6-2: Initial set-up for injection (direct-injection) of the laboratory scale sample from the sample cylinder into the SAUNA-II system.......................................... 23 


\section{Tables}

Table 2-1: Data of spontaneous fission half-lives and yields of selected isotopes [3], [4]... 8

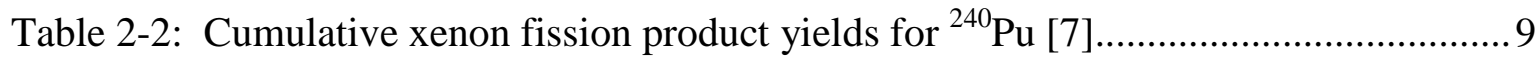

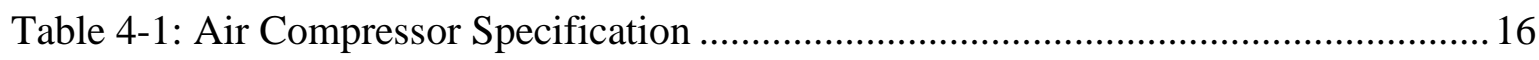

Table 5-1: TX-118 ${ }^{240} \mathrm{Pu}$ mass as a function of holdup time and venting rate ...................20

Table 6-1: Actinide masses in Pu nitrate sample.......................................................... 21

Table 6-2: Results of laboratory scale sample taken on Dec. 01, 2014 ........................... 24

Table 6-3: Calculated hold-up time and ${ }^{240} \mathrm{Pu}$ mass for Dec. 01, 2014 sample.................. 24

Table 6-4: Results of glove box sample taken on April 09, 2015...................................25

Table 6-5: Calculated hold-up time and ${ }^{240} \mathrm{Pu}$ mass for April 09, 2015 sample................. 25

Table 7-1: Calculated uncertainties for ${ }^{240} \mathrm{Pu}$ mass of the April 09, 2015 sample. Each uncertainty represents the percent above (+) and below (-) the computed mass..........26 


\subsection{Introduction}

The detection and quantification of plutonium in difficult to access locations, such as underground nuclear waste tanks, normally requires the collection of physical samples followed by radiochemistry to remove interfering isotopes and/or other radiometric techniques (e.g., mass spectroscopy or radiation counting). The team at Pacific Northwest National Laboratory is exploring a technique that allows for the indirect detection and possible quantification of plutonium using existing ultra-sensitive detection methods for radioactive xenon [1], [2]. This method utilizes the relatively high spontaneous fission rate of ${ }^{240} \mathrm{Pu}$ which produces various xenon isotopes. Xenon, as a noble gas, does not chemically interact with other materials present. This chemical inertness increases the probability that the radio-xenon isotopes are able to escape the immediate surroundings of the plutonium bearing materials and can be collected by gas sampling methods. If the isotopic information of the plutonium likely present in the sampled are known or can be estimated, then the amount of ${ }^{240} \mathrm{Pu}$ can be used to infer the total mass of plutonium.

Since waste tanks are often very complex with respect to the internal configuration of material, with layers of liquid, sludge and solids, it is likely that some xenon may be delayed or 'held up' in waste material prior to reaching the tank headspace. However, since several xenon radioisotope ratios are produced in spontaneous fission, it is possible to use their measured concentrations to estimate not only the mass, but also the migration time to the headspace and the venting rate of the tank. This approach does assume the xenon isotopes and ${ }^{240} \mathrm{Pu}$ are in isotopic equilibrium, which would be a minor source of error if conditions in the waste tank remain the same for approximately 70 days, or six half-lives of ${ }^{131 \mathrm{~m}} \mathrm{Xe}$.

These radioisotopes exhibit high mobility and may be measured using techniques normally used for the detection of nuclear explosions. In this report, these short-lived xenon isotopes are measured in order to infer the amount of ${ }^{240} \mathrm{Pu}$ in both a Hanford waste tank (TX-118) and in a simple laboratory experiment with a well-characterized plutonium-nitrate solution.

\subsection{Gas Accumulation from Spontaneous Fission in Waste Tanks}

\subsection{Generation of Radioxenon by Spontaneous Fission}

Plutonium-240 decays primarily by $\alpha$-emission. However, a small fraction of the decays $\left(5.7 \times 10^{-8}\right)$ occur by spontaneous fission. An effective spontaneous fission half-life, $\tau_{\mathrm{SF}}$, can be defined as the observed half-life divided by the branching ratio $(B R)$ for spontaneous fission: 


$$
\tau_{S F}=\frac{\tau_{1 / 2}}{B R}
$$

The effective spontaneous fission half-life for ${ }^{240} \mathrm{Pu}$ is $1.15 \times 10^{11}$ years. Table $2-1$ shows the spontaneous fission half-life and spontaneous fission fractions for several transuranic isotopes including ${ }^{240} \mathrm{Pu}$. Special consideration may need to be given to several isotopes, ${ }^{244} \mathrm{Cm}$ in particular, as they too can produce radio-xenon isotopes by spontaneous fission. These other isotopes, if present in sufficient concentrations, may require a correction factor to be applied.

Table 2-1: Data of spontaneous fission half-lives and yields of selected isotopes [3], [4].

\begin{tabular}{|l|l|l|l|}
\hline Isotope & $\begin{array}{l}\text { Half-Life } \\
\text { years })\end{array}$ & $\begin{array}{l}\text { Spontaneous Fission } \\
\text { Branching Ratio }(B R)\end{array}$ & $\begin{array}{l}\text { Spontaneous Fission } \\
\text { Half-Life (years) }\end{array}$ \\
\hline${ }^{\mathbf{2 5 2}} \mathbf{C f}$ & $2.646 \times 10^{0}$ & $3.1 \times 10^{-2}$ & $85.6 \times 10^{0}$ \\
\hline${ }^{244} \mathbf{C m}$ & $18.1 \times 10^{0}$ & $1.3 \times 10^{-6}$ & $1.39 \times 10^{7}$ \\
\hline${ }^{\mathbf{2 3 8}} \mathbf{P u}$ & $87.7 \times 10^{0}$ & $1.9 \times 10^{-9}$ & $4.62 \times 10^{10}$ \\
\hline${ }^{\mathbf{2 3 9}} \mathbf{P u}$ & $2.41 \times 10^{4}$ & $3.0 \times 10^{-12}$ & $8.04 \times 10^{15}$ \\
\hline${ }^{240} \mathbf{P u}$ & $6.56 \times 10^{3}$ & $5.7 \times 10^{-8}$ & $1.15 \times 10^{11}$ \\
\hline${ }^{242} \mathbf{P u}$ & $3.75 \times 10^{5}$ & $5.5 \times 10^{-6}$ & $6.79 \times 10^{10}$ \\
\hline${ }^{\mathbf{2 3 5}} \mathbf{U}$ & $7.04 \times 10^{8}$ & $7.0 \times 10^{-11}$ & $1.01 \times 10^{19}$ \\
\hline${ }^{\mathbf{2 3 8}} \mathbf{U}$ & $4.47 \times 10^{9}$ & $5.0 \times 10^{-7}$ & $8.94 \times 10^{15}$ \\
\hline
\end{tabular}

During spontaneous fission, a parent nucleus splits into two fission products that follow a mass distribution similar to that of neutron-induced fission [5]. In the case of ${ }^{240} \mathrm{Pu}$, there exists very little experimental data for the mass distribution of spontaneous fission products in literature. However, theoretical calculations of the distribution for the cumulative postevaporation mass yields are available and are shown in Figure 2-1 [6]. For xenon mass 133 and 135 , these values are $8.35 \%$ and $8.87 \%$, respectively. 


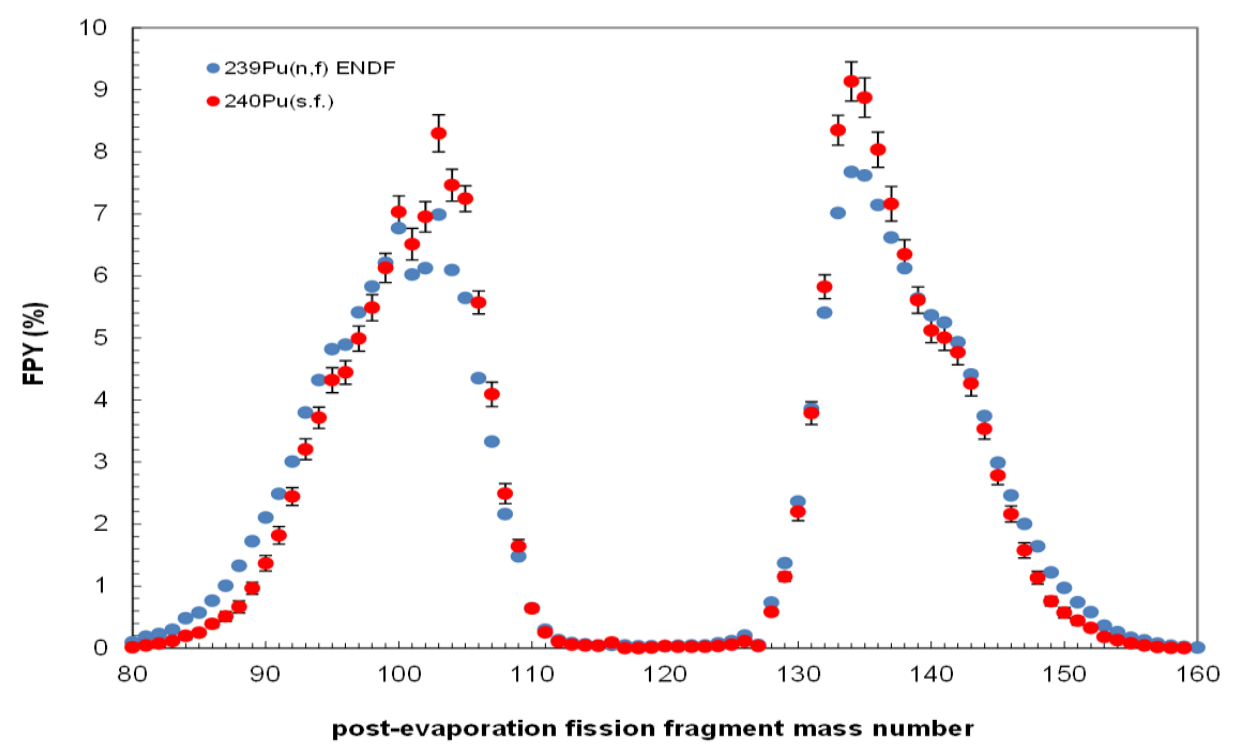

Figure 2-1: Theoretical cumulative mass yields for ${ }^{240} \mathrm{Pu}$ spontaneous fission

The key xenon isotopes are produced both directly (independent) fission products and indirectly through the decay of iodine and other nuclides on the corresponding isobaric chain.

The xenon isotopes of interest are among the higher yield fission products. Table 2-2 shows the assumed cumulative (direct plus indirect routes) or chain yields of the important xenon isotopes produced in ${ }^{240} \mathrm{Pu}$ spontaneous fission.

Table 2-2: Cumulative xenon fission product yields for ${ }^{240} \mathrm{Pu}$ [7].

\begin{tabular}{|l|l|l|l|}
\hline Isotope & Half-life (d) & Decay Constant $\left(\mathrm{s}^{-1}\right)$ & $\begin{array}{l}\text { Cumulative Spontaneous } \\
\text { Fission Yield (\%) }\end{array}$ \\
\hline${ }^{131 \mathrm{~m}} \mathbf{X e}$ & 11.84 & $6.748 \times 10^{-7}$ & 0.0412 \\
\hline${ }^{133} \mathbf{X e}$ & 5.248 & $1.53 \times 10^{-6}$ & 8.35 \\
\hline${ }^{133 \mathrm{~m}} \mathbf{X e}$ & 2.198 & $3.65 \times 10^{-6}$ & 0.240 \\
\hline${ }^{135} \mathbf{X e}$ & 0.3808 & $2.11 \times 10^{-5}$ & 8.87 \\
\hline
\end{tabular}

\subsection{Mathematical Model}

Single-shell tanks at the Hanford site are vented in order to maintain the concentration of explosive gasses below the flammability limits. Tanks are either actively or passively vented, the latter being driven by atmospheric barometric fluctuations, wind currents passing over vents in the tank and other lesser effects. Passive venting flow rates in and out of the tank can be as high as $0.012 \mathrm{~m}^{3} / \mathrm{s}\left(25 \mathrm{ft}^{3} / \mathrm{min}\right)$ [8]. For simplicity, the model created for the venting of these tanks uses a constant airflow, $F$. This airflow, F, can flow both into and out of the tank with a headspace volume of $V$, Figure 2-2. 


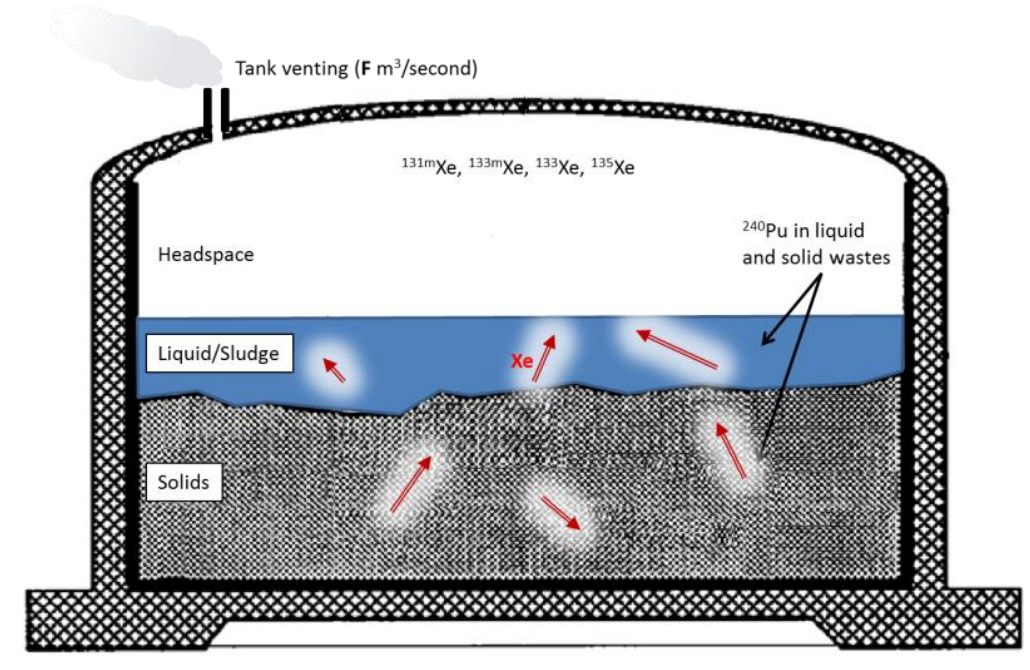

Figure 2-2: Schematic for calculation of flow into and out of tank, used for calculating the effect of dilution of radioxenon in the headspace of the waste tank.

Xenon and iodine isotopes produced from spontaneous fission can be produced in any region of the tank where plutonium is present. Diffusion serves as the primary transport mechanism out of the solid and liquid waste and into the headspace. However, it is important to note that unlike xenon, iodine is chemically reactive. For the indirectly produced Xe from I decay, this I chemical reactivity creates an effective holdup time. In this study, this reactivity will be empirically addressed through the use of a "holdup" time $\left(t_{H}\right)$ that represents the average time for the gaseous fission products to migrate to the headspace.

The governing equations for the accumulation of xenon isotopes inside a tank headspace from ${ }^{240} \mathrm{Pu}$ spontaneous fission are developed below. For times less than $\mathrm{t}_{\mathrm{H}}$, the only loss term for the xenon concentration is radioactive decay. Equations (1a) and (1b) govern the decay of ${ }^{240} \mathrm{Pu}$ $\left(\mathrm{N}_{\mathrm{Pu}}\right)$ and the production and decay of a specific xenon isotope $\left(\mathrm{N}_{\mathrm{Xe}}\right)$

$$
\begin{aligned}
& \frac{d N_{P u}}{d t}=-\lambda_{P u} N_{P u} \\
& \frac{d N_{X e}}{d t}=f_{X e} \lambda_{P u} N_{P u}-\lambda_{X e} N_{X e} \text { for } 0<t<t_{H} \\
& f_{X e}=B R \chi_{X e}
\end{aligned}
$$

Where $\chi_{X e}$ is the spontaneous fission yield of the Xe radioisotope, $\lambda_{\mathrm{Pu}}$ is the decay constant for ${ }^{240} \mathrm{Pu}$, and $\lambda_{\mathrm{Xe}}$ is the decay constant of the Xe radioisotope.

The solution to these equations is: 


$$
N_{X e}(t)=\frac{f_{X e} \lambda_{P u} N_{P u}^{0}}{\lambda_{X e^{-}-\lambda_{P u}}}\left(e^{-\lambda_{P u} t}-e^{-\lambda_{X e} t}\right) \text { for } 0<t<t_{H}
$$

Here, $\mathrm{N}_{\mathrm{Pu}}^{0}$ is the initial concentration of ${ }^{240} \mathrm{Pu}$ in the tank. After the gas reaches the headspace, venting to and from the environment results in another loss term. The venting rate, $\mathrm{F}(\mathrm{m} 3 / \mathrm{sec}$ ), and the headspace volume, $\mathrm{V}\left(\mathrm{m}^{3}\right)$, are assumed to be known. The source of xenon from the waste into the headspace, $\mathrm{S}_{\mathrm{H}}$, is the derivative of equation (2) evaluated at time $t_{H}$.

$$
S_{H}=\left.\frac{d N_{X e}}{d t}\right|_{t_{H}}=\frac{f_{X e} \lambda_{P u} N_{P u}^{0}}{\lambda_{X e}-\lambda_{P u}}\left(\lambda_{X e} e^{-\lambda_{X e} t_{H}}-\lambda_{P u} e^{-\lambda_{P u} t_{H}}\right)
$$

Equation (3) can be used as the source term for gas in the headspace, where $\mathrm{N}_{\mathrm{xe}}^{\mathrm{H}}$ is identified as the concentration of a specific xenon isotope in the headspace. The governing equation for the gas in the headspace is then:

$$
\frac{d N_{X e}^{H}}{d t}=S_{H}-\lambda_{X e} N_{X e}-\frac{F}{V} N_{X e} \text { for } 0<t<\infty
$$

The solution is:

$$
\begin{gathered}
N_{X e}^{H}(t)=\frac{f_{X e} \lambda_{P u} N_{P u}^{0}}{\lambda_{X e}-\lambda_{P u}}\left(\lambda_{X e} e^{-\lambda_{X e} t_{H}}-\lambda_{P u} e^{-\lambda_{P u} t_{H}}\right)\left(\frac{1-e^{-\lambda_{X e}^{T} t}}{\lambda_{X e}^{T}}\right) \\
N_{P}^{0}=\text { Number of Pu240 atoms at time }=0 \\
\lambda_{P}=\text { Pu240 decay constant } \\
\lambda_{x}=\text { decay constant for nuclide "x" } \\
\lambda_{x}^{T}=\lambda_{x}+\frac{F}{V}=\text { the total decay constant for nuclide } x
\end{gathered}
$$

It is recognized that ${ }^{240} \mathrm{Pu}$ decay is negligible during the sampling campaign, so assuming equilibrium of $\mathrm{Xe}$ radioisotopes:

$$
N_{x}^{H}(t \gg 0)=\frac{f_{x} \lambda_{P} N_{P}^{0}}{\lambda_{x}^{T}} e^{-\lambda_{x} t_{H}}
$$

For most practical purposes, equation (6) is sufficiently accurate for the applications in this report. It is important to note, however, that uncertainty in the mass yield for each measured xenon isotope is a direct source of possible error. 
Modeling of the direct fission product production and resulting decay chains were neglected; instead radioisotope production terms were assigned based on the cumulative mass yield for each of the xenon isotopes. Since much of the xenon is produced by decay of the corresponding iodine isotope, this could have a large effect on the hold-up time due to the chemical reactivity of iodine.

\subsection{Measurement Methods}

\subsection{Swedish Automated Noble Gas Analysis System}

The SAUNA-II is a completely automated atmospheric sampling system widely employed in the International Monitoring System of the Comprehensive Nuclear Test-Ban Treaty Organization to separate and measure radioxenon with high precision using beta-gamma coincidence counting [9]. The samples acquired and analyzed for this project were analyzed in the PNNL SAUNA-II shown in Figure 3-1 and schematically in Figure 3-2.

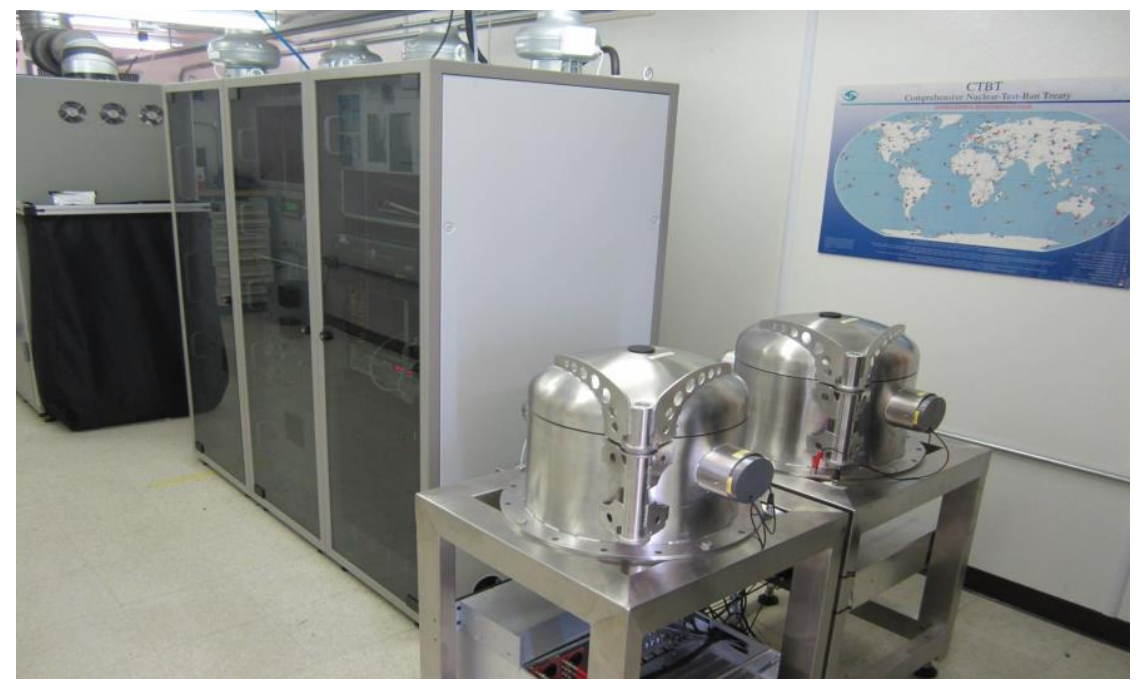

Figure 3-1: SAUNA-II System located at Pacific Northwest National Laboratory 


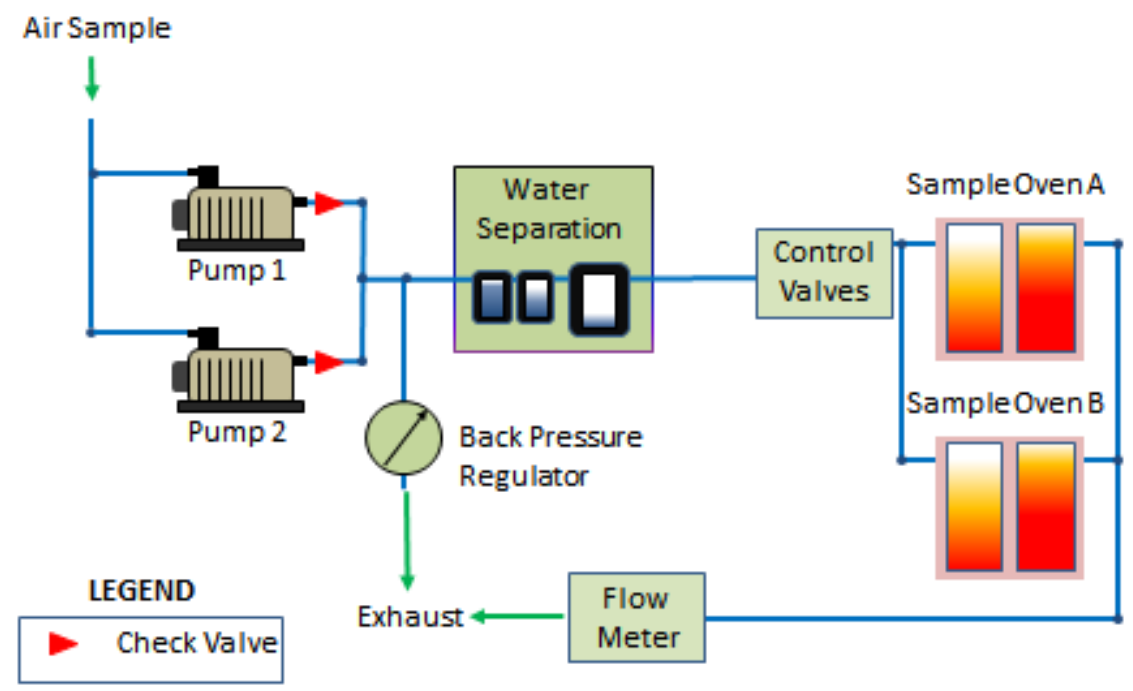

Figure 3-2: PNNL SAUNA-II sampling hardware schematic

Processing gas samples for the isolation of xenon and rejection of radon requires approximately 18 hours. The SAUNA-II system has very high extraction efficiency of xenon $(>90 \%)$ such that a $16 \mathrm{~m}^{3}$ atmospheric sample yields approximated $1.2 \mathrm{cc}$ of xenon. After processing, the isolated xenon sample is counted in a coincidence beta-gamma detector for 12 hours. Subsequent to the counting, the samples are transferred to $500 \mathrm{ml}$ archive bottles and stored for 6 days The SAUNA-II system is designed to measures xenon isotopes to concentrations below $0.2 \mathrm{mBq} / \mathrm{m}^{3}$.

Gas samples are typically collected in cylinders and transported to the SAUNA-II. These gas cylinders were injected into the SAUNA-II system using a down-stream dual-stage pressure reducing regulator. In order to accomplish the quantitative analysis of the acquired samples, careful consideration was required to modify the SAUNA-II system in order to enable the immediate switch over from continuously acquired atmospheric samples to discrete cylinderbased samples. As illustrated in Figure 3-2, the SAUNA-II system is comprised of two compressor pumps operating in parallel to supply atmospheric samples to two separate sampling collection ovens.

During normal operation, the SAUNA-II system acquires a complete atmospheric sample every 12 hours. The two sampling pumps supply air to the sampling ovens at 7.1 bar with a flow rate of approximately 22.1 SLM. Parameters for normal atmospheric sampling are shown in Table 3-3. 
Table 3-3: Standard sampling parameters for the PNNL SAUNA-II.

\begin{tabular}{||c|c|c|c||}
\hline $\begin{array}{c}\text { Sample Injection } \\
\text { Duration }\end{array}$ & $\begin{array}{c}\text { Supplied } \\
\text { Pressure }\end{array}$ & $\begin{array}{c}\text { Flow } \\
\text { Rate }\end{array}$ & $\begin{array}{c}\text { Sampled } \\
\text { Volume }\end{array}$ \\
\hline \hline 12 hours & $\sim 7.1 \mathrm{bar}$ & $\sim 22 \mathrm{slm}$ & $\sim 16 \mathrm{~m}^{3}$ \\
\hline
\end{tabular}

In order to fully utilize the SAUNA-II's capability to quantitatively analyze gas samples, considerable effort was exerted to modify the SAUNA-II system to inject samples in a manner that exactly mimics normal operations. It was determined that the introduction of a 3-way valve immediately following the water separation unit would be the optimal method to inject samples to the SAUNA-II system. This modification allowed complete isolation of the sampling pumps, back pressure regulator and water separation units from the sample gas injection. This does present a slight disadvantage in that the injected sample gas does not go through the water separation unit. However, considerable effort was employed to dry the sampled gas as it was collected. As illustrated in Figure 3-3, a simple 3-way valve was placed between the water separation unit and the control valves of the sampling control unit.

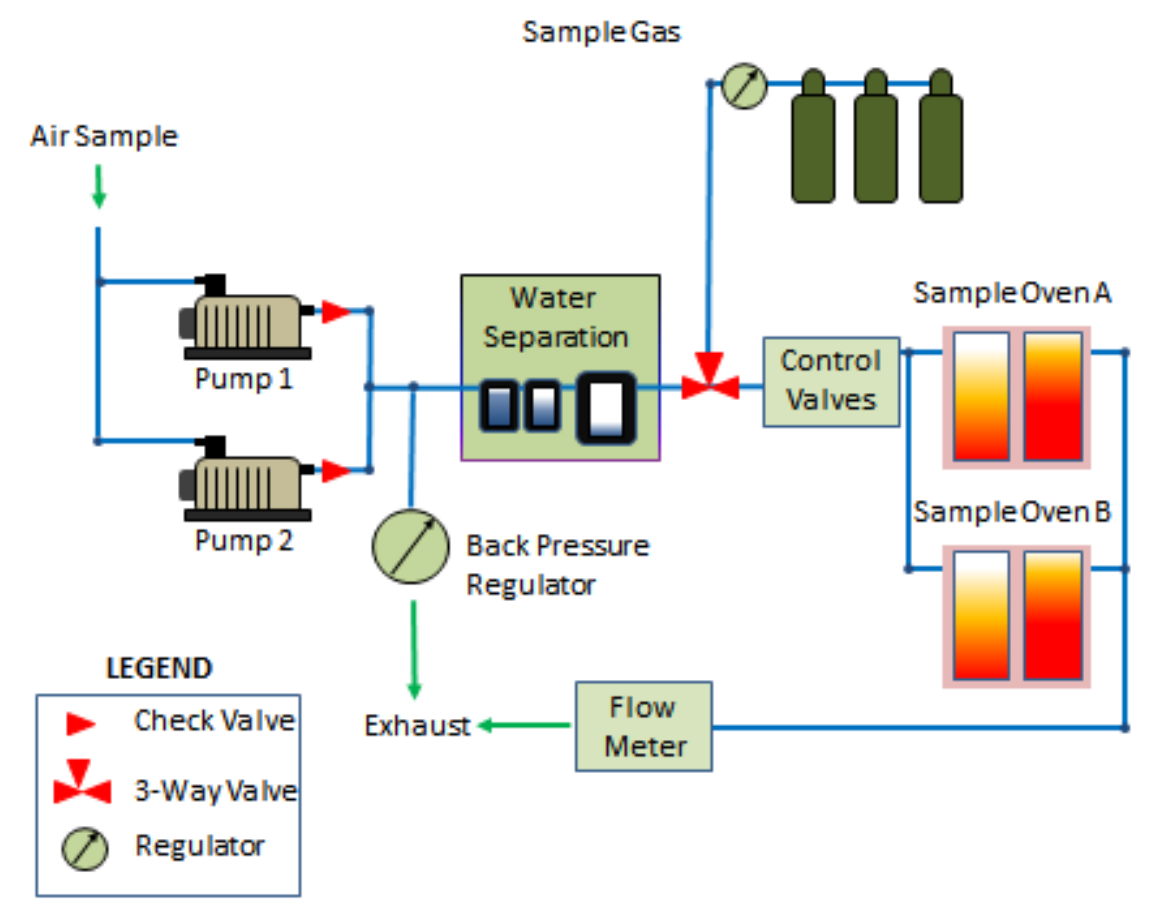

Figure 3-3: Modification to the SAUNA sampling system. A 3 way valve was introduced after the water separation unit. 


\subsection{Waste Tank Sample Collection Procedure (Tank TX-118)}

Initial efforts to demonstrate the sampling capabilities and procedures were performed at the Hanford Waste Tank Facility located in the Hanford Nuclear Reservation near Richland, Washington. The high levels of radioactivity contained in many of the tanks present a good opportunity to demonstrate the indirect sampling processes.

Considerable review was performed by the team on the history and contents of various tanks located at the tank farm in order to select a good candidate for a sampling campaign. There were at one time 117 one-million gallon tanks at Hanford. Parameters such as access to tank head space and tank ventilation were also taken into consideration. Ultimately, Tank TX-118 was selected. This Tank (TX-118) is a single shell nuclear waste storage tank constructed in 1947 through 1948 with a total capacity of $2,869 \mathrm{~m}^{3}$ and a headspace volume of 2,684 $\mathrm{m}^{3}$. TX-118 contains a variety of Pu-reprocessing wastes including ${ }^{90} \mathrm{Sr},{ }^{137} \mathrm{Ce},{ }^{239} \mathrm{Pu},{ }^{240} \mathrm{Pu}$, and ${ }^{241} \mathrm{Am}$. Extremely high radioactivity levels [10] (>17 kCi) make direct sampling of the tank unpractical, and a good candidate for the team to focus its efforts.

In order to accomplish the sample acquisition, the sampling team inserted a $2.5 \mathrm{~cm}$ polypropylene braided hose through the $7.5 \mathrm{~cm}$ diameter sight-glass of the tank instrumentation, as illustrated in Figure 4-1. This hose was inserted to a depth of approximately 10 meters in the tank head space. The opening was then sealed with tape and a plastic bag was sealed around the opening. Two large diameter ( $6 \mathrm{in} / 12.7 \mathrm{~cm}$.) particulate filters were placed in series on the lowpressure side of the compressor near the sampling location in order to prevent particle contamination from entering the system. The glass-fiber filters, which have an efficiency of 99.9\% removal of particles greater than $0.3 \mu \mathrm{m}$, were contained in the filter housing. 


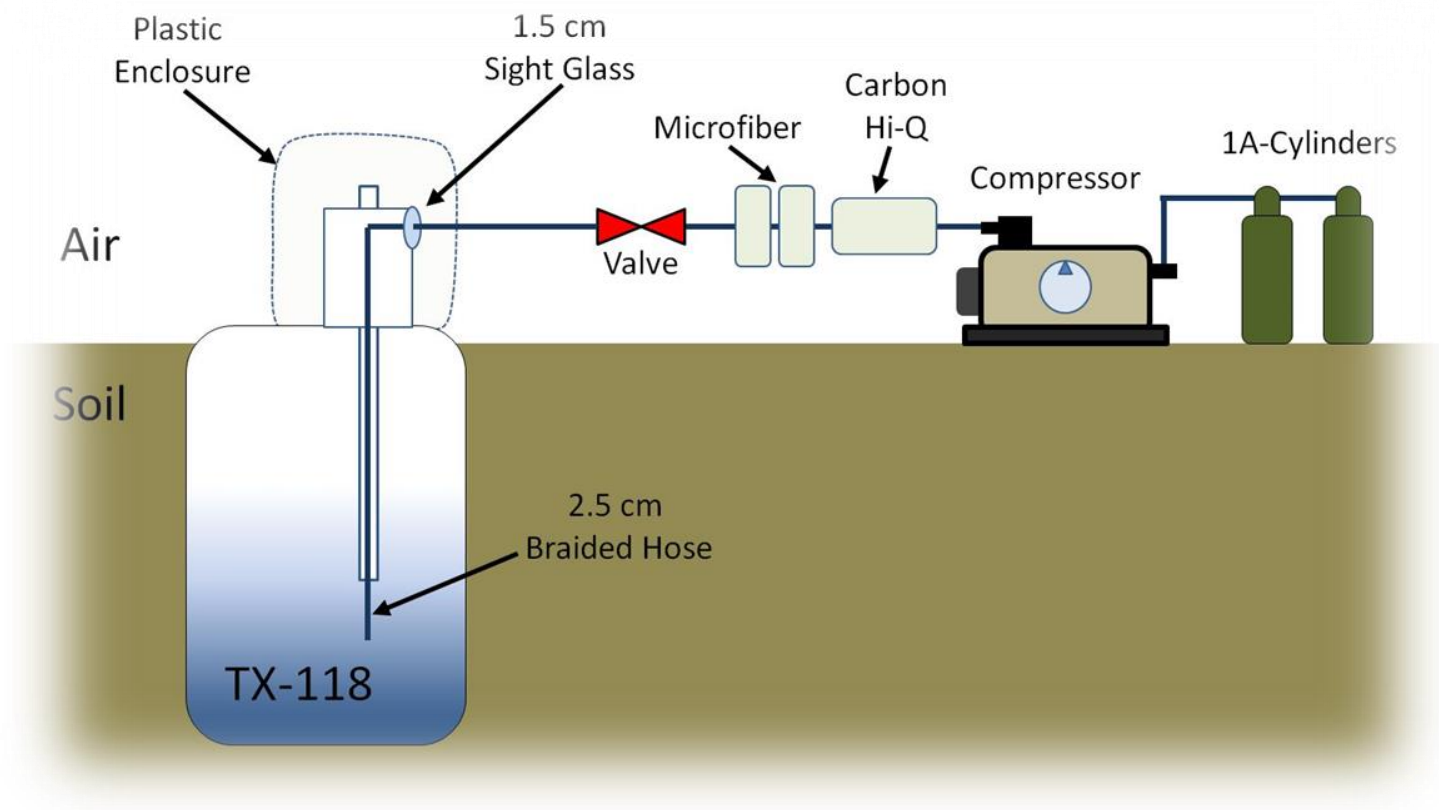

Figure 4-1: Schematic of waste tank sampling.

After the hose was inserted and the opening sealed from the ambient environment, samples from the tank head space were collected using a Max Air $^{T M}-55$ multistage air compressor. Compressor specifications are contained in Table 4-1.

Table 4-1: Air Compressor Specification

\begin{tabular}{|ll|}
\hline \multicolumn{1}{|c|}{ Specification } & \multicolumn{1}{c|}{ Max Air $^{\mathrm{TM}}-55$ Compressor } \\
\hline Electrical Requirement & $220 \mathrm{~V}, 60 \mathrm{~Hz}, 1 \varnothing$ \\
\hline Motor & $7.5 \mathrm{HP}(5.5 \mathrm{~kW})$ \\
\hline Capacity & $10.8 \mathrm{SCFM}(305 \mathrm{slm})$ \\
\hline Maximum pressure & 5000 psi $(206 \mathrm{bar})$ \\
\hline Typical Use & Breathing Tanks (SCUBA) \\
\hline
\end{tabular}

Two high-pressure type 1A cylinders were pressurized with the sampled air to 3000 psig (206 bar) for a total sampled air volume of approximately $24 \mathrm{~m}^{3}$. Physical specifications for type-1A cylinders are presented in Table 4-2. The cylinders were filled with sample gas while secured inside of the enclosed sampling trailer (Figure 4-2Error! Reference source not found.). A gas manifold, capable of 4000 psi (310 bar), was utilized to connect the compressor to the cylinders. 5 hours on compression from the waste tank was required to fill the sample cylinders to the desired pressure. 


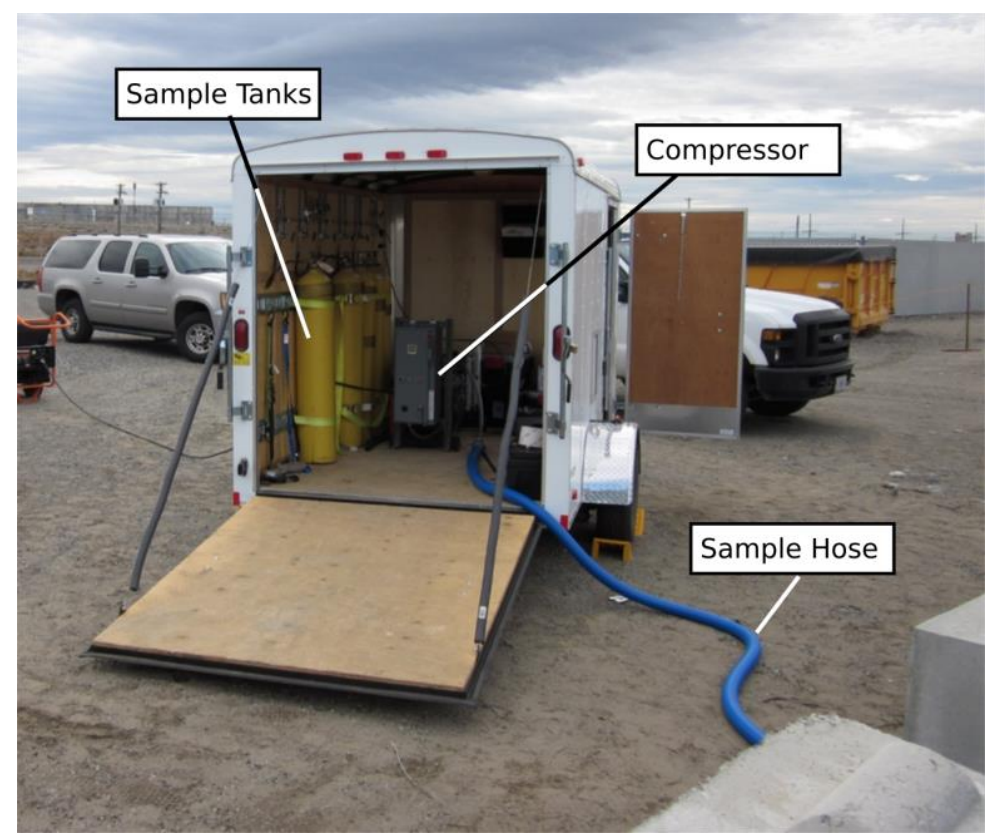

Figure 4-2: Sampling trailer deployed at a sampling site.

After the samples were collected, radiological safety technicians surveyed the filters once every 24 hours. Considerable radioactivity was found in each filter and was attributed to the accumulation of radon. This assumption proved to be correct, as the radioactivity dropped significantly during each measurement and the samples were determined to be safe from tank contamination after 5 days.

Table 4-2: Cylinder Specification

\begin{tabular}{|ll|}
\hline Specification & High Pressure "1A“ Cylinder \\
\hline Internal volume (STP) & 43.8 liter \\
\hline Maximum pressure & $4500 \mathrm{psi}(310 \mathrm{bar})$ \\
\hline Target fill pressure & $4000 \mathrm{psi}(206 \mathrm{bar})$ \\
\hline Capacity at 206 bar & $12 \mathrm{~m}^{\wedge} 3$ \\
\hline${ }^{2}$ Dimensions (diameter $\times$ height.) & $23 \mathrm{~cm} \times 130 \mathrm{~cm}$ \\
\hline Nominal weight $(\mathrm{kg})$ & 55 \\
\hline
\end{tabular}

The sample cylinders from tank TX-118 were transported from the Hanford Waste Tank Facility to Pacific Northwest National Laboratory, where a SAUNA-II system is continuously operated, for processing and analysis. The SAUNA-II processing and analysis is well documented in several references [2], [9], [11]. After the analysis in the SAUNA-II system, the 
radio-xenon sample was transferred to a $500 \mathrm{cc}$ archive bottle which enabled longer duration, more detailed analysis.

An additional set of measurements were made using a similar laboratory-based beta-gamma based radioxenon measurement system to validate the SAUNA-II measurements by using xenon gas samples archived by the SAUNA-II system. The second set of measurements was critical since the initial levels of ${ }^{133} \mathrm{Xe}$ measured in the first samples interfered with measurement of the

much lower ${ }^{131 \mathrm{~m}} \mathrm{Xe}$ activity, making that isotope fall below detection limits. After an additional one month decay period, the ${ }^{131 \mathrm{~m}} \mathrm{Xe}$ was observable above the ${ }^{133} \mathrm{Xe}$ signal.

\subsection{Measurement and Results}

Initial planning on the analysis of the Hanford tank sample was aimed towards the ability to acquire 4 separate isotope activities, ${ }^{133 \mathrm{~m}} \mathrm{Xe},{ }^{135} \mathrm{Xe},{ }^{133} \mathrm{Xe}$ and ${ }^{131 \mathrm{~m}} \mathrm{Xe}$. However, an abundance of caution regarding the presence of radioactivity in the sampling filters (attributed to the presence of radon gas) resulted in the samples remaining at the TX-118 site for 5 days. Therefore, given the 2.2day half-life ${ }^{133 \mathrm{~m}} \mathrm{Xe}$ and the $9.1 \mathrm{hr}$ half-life ${ }^{135} \mathrm{Xe}$, these isotopes were expected to decay away to limits below the capabilities of analysis systems. Therefore, in these measurements, only two xenon isotopes were measures, ${ }^{131 \mathrm{~m}} \mathrm{Xe}$ and ${ }^{133} \mathrm{Xe}$. The measured values of ${ }^{131 \mathrm{~m}} \mathrm{Xe}$ and ${ }^{133} \mathrm{Xe}$ activity, corrected to sample collection time, were 0.0097 and $2.68 \mathrm{~Bq} / \mathrm{m}^{3}$, respectively. Figure 5-1 shows the typical results from the analysis with the conversion electron from ${ }^{131 \mathrm{~m}} \mathrm{Xe}$ underneath the ${ }^{133} \mathrm{Xe}$ beta continuum. 


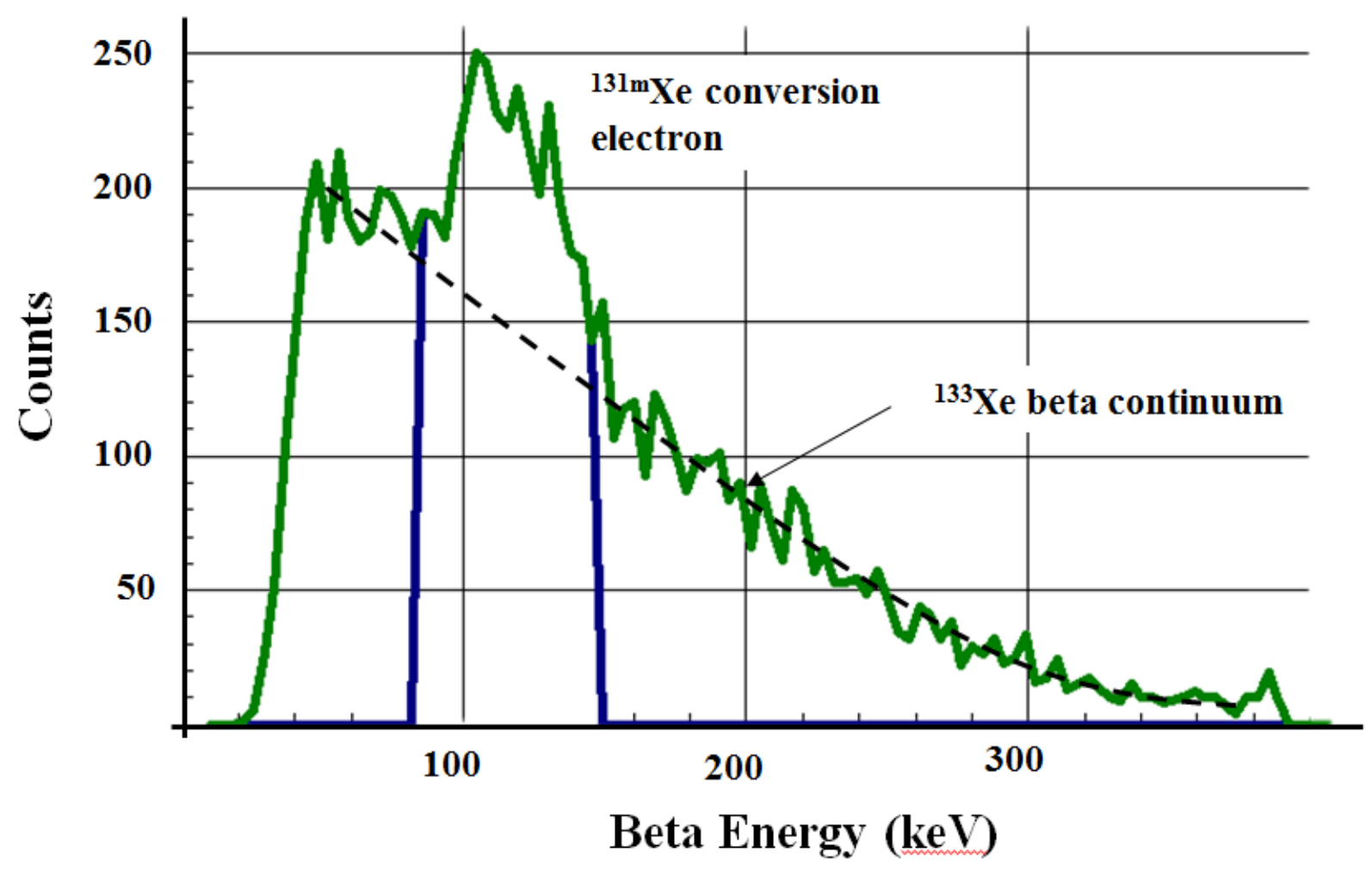

Figure 5-1: Beta spectrum in coincidence with the $30-\mathrm{keV}$ x-ray peak of the one of the samples of headspace gas, clearly showing the expected conversion electron from ${ }^{131 \mathrm{~m}} \mathrm{Xe}$ on top of the beta continuum from ${ }^{133} \mathrm{Xe}$.

Only two xenon isotopes could be measured due to the 5 day delay in sample measurement. Since there are three unknowns (the ${ }^{240} \mathrm{Pu}$ mass, the holdup time and the venting rate), only a range of possible ${ }^{240} \mathrm{Pu}$ masses can be computed. In this case, the activity ratio of ${ }^{131 \mathrm{~m}} \mathrm{Xe} /{ }^{133} \mathrm{Xe}$ is used as a function of both holdup time and venting rate. The use of this ratio eliminates the ${ }^{240} \mathrm{Pu}$ mass. Then, a set of self-consistent holdup times and venting rates can be determined as shown in the Figure 5-2. 


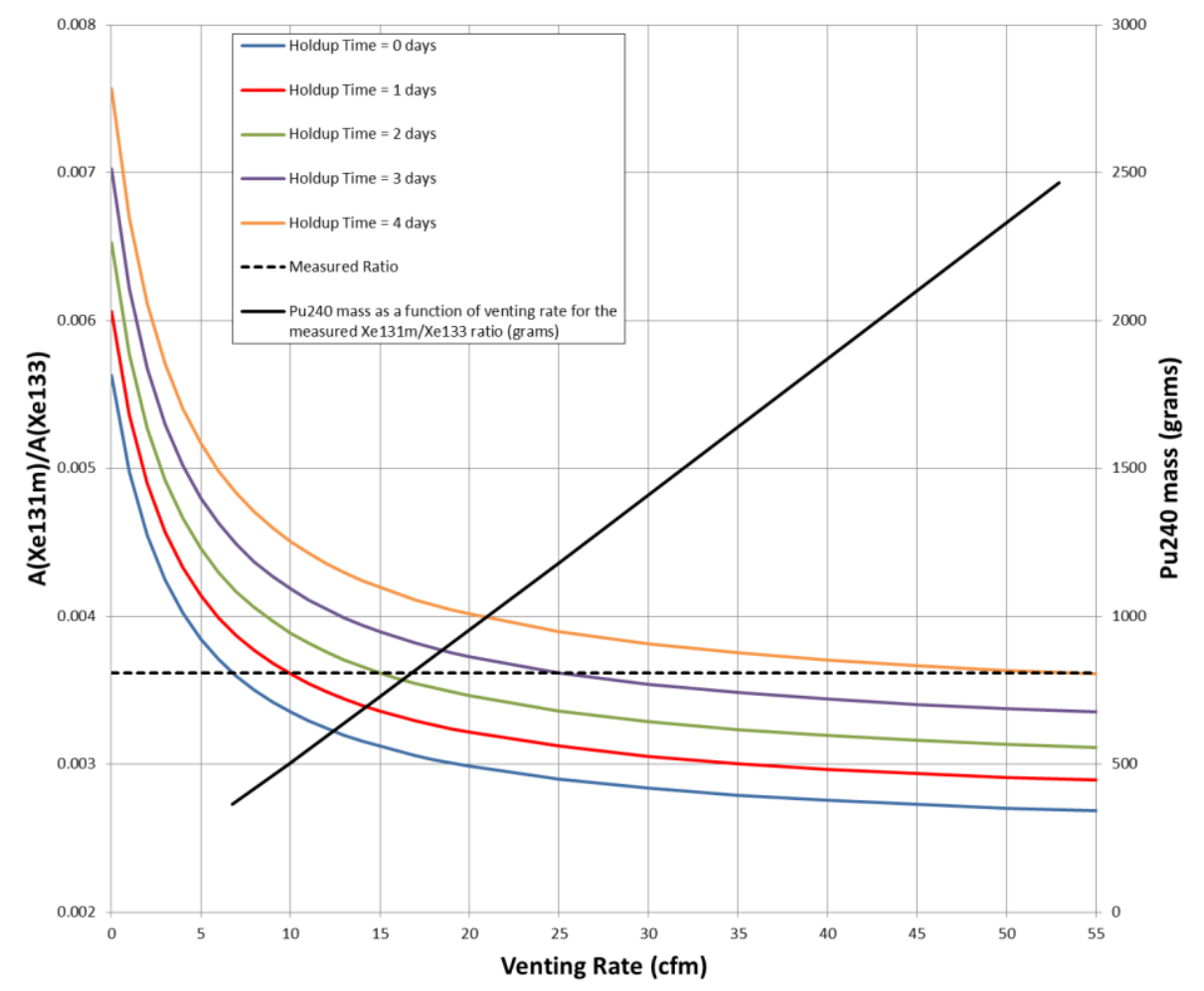

Figure 5-2: ${ }^{131 \mathrm{~m}} \mathrm{Xe} /{ }^{133} \mathrm{Xe}$ Activity Ratio as a Function of Venting Rate

In Figure 5-2, the equilibrium ${ }^{131 \mathrm{~m}} \mathrm{Xe} /{ }^{133} \mathrm{Xe}$ activity ratio is plotted as a function of venting rate for a variety of assumed holdup times. The measured ratio of 0.0036 is shown as a dashed line. The location where this line intercepts the holdup time (shown in Table 5-1) curves corresponds to a venting rate and mass that are self-consistent. The solid black line is the ${ }^{240} \mathrm{Pu}$ mass (read on the right hand side axis) that is consistent with the measured ratio, holdup time and venting rate according to the following relation:

$$
N_{p}^{0}=\frac{\lambda_{x}^{T} N_{x}^{M e a s u r e d}}{f_{x} \lambda_{P} e^{-\lambda_{x} t_{H}}}
$$

Table 5-1: TX-118 ${ }^{240} \mathrm{Pu}$ mass as a function of holdup time and venting rate

\begin{tabular}{|c|c|c|}
\hline Holdup time (days) & $\mathbf{F}(\mathbf{c f m})$ & ${ }^{\mathbf{2 4 0}} \mathbf{P u}$ (grams) \\
\hline 0 & 6.8 & 360 \\
\hline 1 & 9.9 & 500 \\
\hline 2 & 15 & 730 \\
\hline 3 & 25 & 1200 \\
\hline 4 & 53 & 2500 \\
\hline
\end{tabular}


Previous work on Hanford tanks has shown that passive venting of the tanks can reach as high as $0.024 \mathrm{~m}^{3} / \mathrm{s}\left(50 \mathrm{ft}^{3} / \mathrm{min}\right)$, though most tanks have lower rates [12]. For tank TX-118, no data exists for the passive flow from the tank during the period leading up to sample collection. Since the maximum venting rate observed in Hanford waste tanks is bounded by about 0.024

$\mathrm{m}^{3} / \mathrm{s}$, these results indicate a possible range of ${ }^{240} \mathrm{Pu}$ mass in tank TX-118 of 0.25 to $1.92 \mathrm{~kg}$. The published estimate of the actual inventory is $3.4-_{-1.7}^{+3.4} \mathrm{~kg}$, which is quite reasonable agreement given the complex nature of the tank, measurement uncertainties and the fact that only two xenon isotopes could be measured.

\subsection{Laboratory Experiment}

While the results from the TX-118 tank sampling effort were encouraging, the research team determined that a laboratory scale experiment would be useful in order to pinpoint the potential sources of error and to refine the measurement methodology. This section details this laboratory scale experiment.

\subsection{Experimental Setup and Sample Collection}

An isolated glovebox was utilized at the Radiochemical Processing Laboratory (RPL) at PNNL. This glove box contained a beaker holding $362 \mathrm{~cm}^{3}$ of a previously characterized plutonium-nitrate solution, shown in Figure 6-1. The mass of the sample was assayed on June 19, 2014, and the results are reported in Table 6-1. The reported quantity of ${ }^{240} \mathrm{Pu}$ within the breaker was determined to be $2.39 \mathrm{~g}$. This provides a sufficiently large mass compared to the other isotopes present to validate the assumption that all radioactive Xe production in the beaker is a result of the spontaneous fission of ${ }^{240} \mathrm{Pu}$. This sample was allowed to remain undisturbed, for approximately 6 months. During this time, the spontaneous fission of ${ }^{240} \mathrm{Pu}$ resulted in the release of radio-isotopes of Xe.

Table 6-1: Actinide masses in Pu nitrate sample.

\begin{tabular}{|ll|}
\hline Nuclide & Mass $(\mathrm{g})$ \\
\hline${ }^{238} \mathrm{Pu}$ & 0.014 \\
\hline${ }^{239} \mathrm{Pu}$ & 20.4 \\
\hline${ }^{240} \mathrm{Pu}$ & 2.39 \\
\hline${ }^{241} \mathrm{Pu}$ & 0.046 \\
\hline${ }^{241} \mathrm{Am}$ & 0.09 \\
\hline
\end{tabular}

In order to transfer the radio-xenon gas out of the beaker, the team flowed $\mathrm{N}_{2}$ gas through the beaker into a pair of Tedlar gas-tight sample bags. The sample is transferred from the bags to a previously evacuated (< 10 mTorr) SUMMA canister with a volume of $33,185+/-100 \mathrm{~cm}^{3}$. Additional $\mathrm{N}_{2}$ was flowed through the sample line to transfer any residual sample gas in the transfer lines and to pressurize the canister and to slightly above atmospheric pressure. The 
volume of the sample and flow gas was measured and tracked throughout the process. The sample in the Summa canister is then volumetrically transferred to evacuated sample containers for injection to the SAUNA-II system.

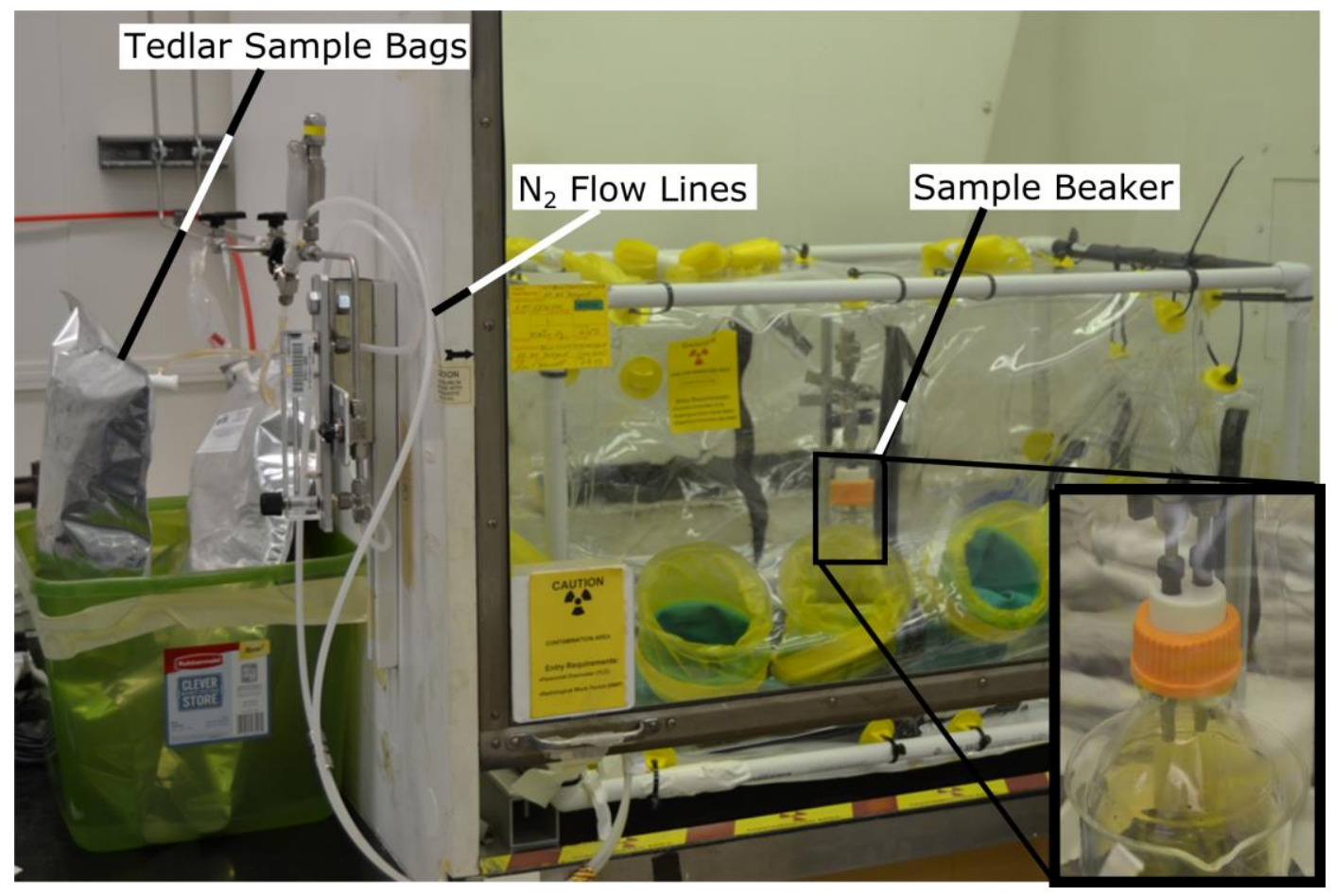

Figure 6-1: Glove box sample collection setup 
The procedure to process and analyze the samples using the SAUNA-II system has been continuously evolving in order to improve the efficiency of the measurement. A first set of measurements was performed by inserting the sample cylinders in parallel to the inlet stream of the SAUNA-II system and allowing normal air to flow through the sample cylinder to transfer the sample into the SAUNA, as shown in Figure 6-2.

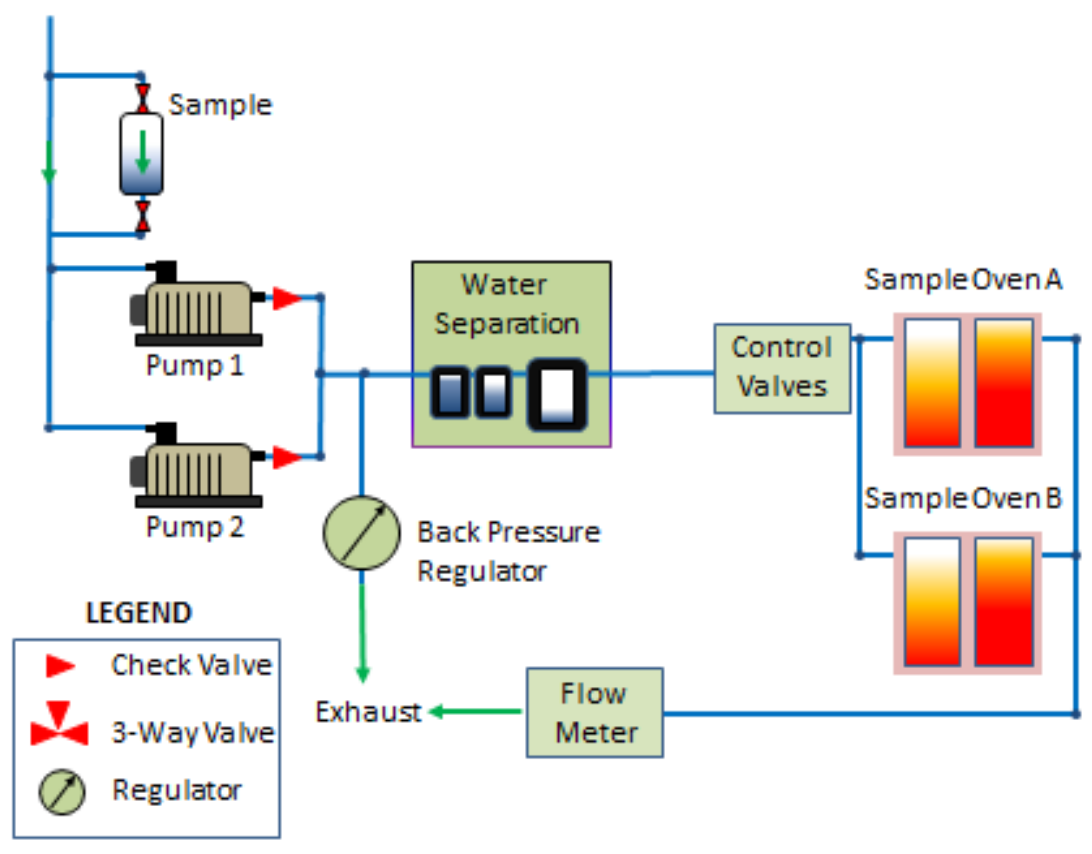

Figure 6-2: Initial set-up for injection (direct-injection) of the laboratory scale sample from the sample cylinder into the SAUNA-II system.

A second procedure was developed by the research team by volumetric expansion of the samples from the laboratory into two evacuated Type IA cylinders. These cylinders are then pressurized to 1500 PSI. Injection of the now compressed sample gas is performed in an identical fashion to the process outline in Section 3.0. The second method has been determined to be far superior to the first method as it allows for the transfer efficiency to be tracked for each specific experiment. 


\subsection{Laboratory Scale Experiment - Measurement and Results}

Two rounds of sample collection from the beaker containing the Pu-nitrate solution were completed on Dec. 01, 2014 and April 09, 2015. The direct inlet stream method for transfer into the SAUNA-II system was used during the first round (Dec 01, 2014) of experiments. The compressed tank method was used for the second round of measurements.

The results of the analysis of the samples using the SAUNA-II system are shown in Table 6-2. The minimum detectable activity (MDA) is reported in the parenthesis. All results corrected for radiological decay to the acquisition start time.

Table 6-2: Results of laboratory scale sample taken on Dec. 01, 2014

\begin{tabular}{|lll|}
\hline \multicolumn{1}{|c|}{ Measurement } & \multicolumn{1}{c|}{ Sample 1-C } & \multicolumn{1}{c|}{ Sample 1-D } \\
\hline Acquisition start (UTC) & $12 / 3 / 201401: 45$ & $12 / 3 / 201413: 45$ \\
\hline$\%$ of sample & $0.5881 \%+/-0.002$ & $6.847 \%+/-0.04$ \\
\hline${ }^{135} \mathrm{Xe}$ Activity & $6.017+/-1.0 \mathrm{mBq}$ & $18.466+/-1.6 \mathrm{mBq}$ \\
\hline${ }^{135} \mathrm{Xe}$ MDA & $2.88 \mathrm{mBq}$ & $2.63 \mathrm{mBq}$ \\
\hline${ }^{133} \mathrm{Xe}$ Activity & $123.667+/-2.422 \mathrm{mBq}$ & $1131.004+/-39.2 \mathrm{mBq}$ \\
\hline${ }^{133} \mathrm{Xe}$ MDA & $2.29 \mathrm{mBq}$ & $2.84 \mathrm{mBq}$ \\
\hline
\end{tabular}

The calculation of the hold-up time (Eq. 6) and the ${ }^{240} \mathrm{Pu}$ mass (Eq. 7) for each sample is shown in Table 6-3. The cumulative uncertainties are shown for the mass calculation, and the sources of these uncertainties are described in Section 7.

Table 6-3: Calculated hold-up time and ${ }^{240} \mathrm{Pu}$ mass for Dec. 01, 2014 sample

\begin{tabular}{|c|c|c|c|}
\hline Sample & Ratio & Hold-Up (h) & ${ }^{240} \mathrm{Pu}$ Mass (g) \\
\hline $1-\mathrm{C}$ & ${ }^{135} \mathrm{Xe} /{ }^{133} \mathrm{Xe}$ & 9.90 & 0.736 \\
\hline $1-\mathrm{D}$ & ${ }^{135} \mathrm{Xe} /{ }^{133} \mathrm{Xe}$ & 13.4 & 0.629 \\
\hline Average & & 11.7 & 0.684 \\
\hline
\end{tabular}

For the first round of measurements on the glove box setup, the calculation of the hold-up time, using ${ }^{135} \mathrm{Xe} /{ }^{133} \mathrm{Xe}$ ratios, results in an average hold-up time of 11.7 hours. It should be noted that two samples (Samples 1-A and 1-B) processed contained too little radioxenon activity to be analyzed. This loss of activity was attributed to large variations in the amount of xenon injection to the SAUNA-II system using the direct injection method outlined in section 6.1. With an 11.7 hour hold-up time, the computed ${ }^{240} \mathrm{Pu}$ mass is $0.683 \mathrm{~g}$ which is $29 \%$ of the accepted mass of ${ }^{240} \mathrm{Pu}$ in the container. It is believed that this discrepancy is the result of inefficient transfer from the sample containers to the SAUNA-II system using the direct injection method.

Following the discrepancy in the first round of measurements, the second sample transfer method was developed, using the type $1 \mathrm{~A}$ cylinders. The results of this second round of measurements the laboratory scale experiment are shown in Table 6-4. 
Table 6-4: Results of glove box sample taken on April 09, 2015

\begin{tabular}{|lll|}
\hline Measurement & Sample 2-A & Sample 2-B \\
\hline$\%$ of sample & $1.94 \%$ & $1.94 \%$ \\
\hline Acquisition start date (UTC) & $4 / 10 / 201513: 45: 00$ & $4 / 11 / 201513: 45: 09$ \\
\hline${ }^{135}$ Xe Activity & $146.8+/-16.6 \mathrm{mBq}$ & $25.2+/-3.16 \mathrm{mBq}$ \\
\hline${ }^{135} \mathrm{Xe}$ MDA & $21.13 \mathrm{mBq}$ & $2.75 \mathrm{mBq}$ \\
\hline${ }^{131 \mathrm{~m}}$ Xe Activity & $26.36+/-7.34 \mathrm{mBq}$ & $0 \mathrm{mBq}$ \\
\hline${ }^{13} \mathrm{~m}$ Xe MDA & $21.1 \mathrm{mBq}$ & $20.9 \mathrm{mBq}$ \\
\hline${ }^{13}$ Xe Activity & $1226.4+/-129.8 \mathrm{mBq}$ & $1126.6+/-119.2 \mathrm{mBq}$ \\
\hline${ }^{133}$ Xe MDA & $3.2 \mathrm{mBq}$ & $7.56 \mathrm{mBq}$ \\
\hline Sample fraction injected to SAUNA & $0.8325 * 50 / 51$ & $0.947 * 50 / 51$ \\
\hline
\end{tabular}

The average hold-up time computed, shown in Table 6-5, using the ${ }^{135} \mathrm{Xe} /{ }^{133} \mathrm{Xe}$ ratio is determined to be $9.3 \mathrm{~h}$, which is in close agreement with the previous round of measurements. This is an expected result since the hold-up time is only dependent on the radioxenon ratios. The resulting ${ }^{240} \mathrm{Pu}$ mass was computed to be $2.21{ }_{-0.59}^{0.81} \mathrm{~g}$, which is in excellent agreement with the assayed mass.

An interesting result was also observed, the hold-up calculated using the ${ }^{131 \mathrm{~m}} \mathrm{Xe} /{ }^{133} \mathrm{Xe}$ ratio for Sample 2-A is dramatically different than that computed using the ${ }^{135} \mathrm{Xe} /{ }^{133} \mathrm{Xe}$ ratio. The ${ }^{131 \mathrm{~m}} \mathrm{Xe} /{ }^{133} \mathrm{Xe}$ ratio provides a hold-up time of approximately 19 days which is not possible given the fact that ${ }^{135} \mathrm{Xe}$ has been detected. The ${ }^{131 \mathrm{~m}} \mathrm{Xe}$ activity appears to be dramatically elevated from what is expected. Further investigation is necessary in order to evaluate the source of this discrepancy as significant measures were taken to maintain sample continuity and cleanliness.

Table 6-5: Calculated hold-up time and ${ }^{240} \mathrm{Pu}$ mass for April 09, 2015 sample.

\begin{tabular}{|lllc|}
\hline Sample & Ratio & Hold-Up $(\mathbf{h})$ & ${ }^{240}$ Pu Mass $(g)$ \\
\hline $2-\mathrm{A}$ & ${ }^{135} \mathrm{Xe} /{ }^{133} \mathrm{Xe}$ & 9.39 & $2.29_{-0.61}^{+0.82}$ \\
\hline 2-B & ${ }^{135} \mathrm{Xe} /{ }^{133} \mathrm{Xe}$ & 9.20 & $2.12_{-0.56}^{+0.79}$ \\
\hline Average & & 9.30 & $2.21_{-0.59}^{+0.81}$ \\
\hline
\end{tabular}

\subsection{Possible Sources of Uncertainty}

Tank TX-118 is known to contain numerous transuranic isotopes including ${ }^{240} \mathrm{Pu},{ }^{244} \mathrm{Cm}$ and others. Other transuranic isotopes could potentially affect results from this method, since approximately $1.9 \mathrm{Ci}$ (corrected to September 2013) of ${ }^{244} \mathrm{Cm}\left(\tau_{1 / 2}=18 \mathrm{yrs}\right)$ was present in the tank during sampling. Referring to Table 2-1, it is estimated that approximately $5 \%$ of the ${ }^{133} \mathrm{Xe}$ detected from the tank headspace was most likely due to the spontaneous fission of ${ }^{244} \mathrm{Cm}$. This 
$5 \%$ estimate assumes that the distribution of ${ }^{244} \mathrm{Cm}$ and ${ }^{240} \mathrm{Pu}$ is approximately the same, with a branching ratio of $5.7 \%$ for ${ }^{244} \mathrm{Cm}$ to ${ }^{133} \mathrm{Xe}$ and a branching ratio of $\sim 7 \%$ for ${ }^{240} \mathrm{Pu}$ to ${ }^{133} \mathrm{Xe}$. In addition, there is also a non-zero, but small neutron flux in the tank that is attributable to $(\alpha, n)$ reactions on light elements and a small amount from spontaneous fission of the transuranic elements. The estimated neutron flux in the tank is on the order of $\sim 2 \mathrm{n} / \mathrm{cm}^{2} / \mathrm{sec}$ [13]. Therefore, it is believed that the contribution to neutron-induced fission of ${ }^{239} \mathrm{Pu}$ and other elements is small.

There are several possible factors that could lead to an underestimate of ${ }^{240} \mathrm{Pu}$. The largest of these factors would be a higher ventilation rate through the waste tank than was assumed. Also, it is possible that the ${ }^{133} \mathrm{Xe}$ created from the spontaneous fission of ${ }^{240} \mathrm{Pu}$ in the tank is trapped for an extended period of time in the solid semi-crystalline form of the waste. Further analysis, which is outside the scope of the current work effort, is required to determine the dominate factor of uncertainty associated with sampling tank TX-118.

There are fundamental uncertainties in all the isotope cumulative yields from ${ }^{240} \mathrm{Pu}$ spontaneous fission $\left(7.23 \%\right.$ to $8.35 \%$ for ${ }^{133} \mathrm{Xe}$, for example) and the spontaneous fission rates. The quantification of these uncertainties has been computed for the second round of measurements from the laboratory scale experiment (see Table 7-1). The cumulative propagation of uncertainty is also shown, which is in excess of $37 \%$. Note that for waste tanks, an additional uncertainty exists in the venting rate and headspace volume, which is not quantified here.

Table 7-1: Calculated uncertainties for ${ }^{240} \mathrm{Pu}$ mass of the April 09, 2015 sample. Each uncertainty represents the percent above (+) and below (-) the computed mass.

\begin{tabular}{|c|c|c|c|c|c|c|c|c|}
\hline \multirow[b]{2}{*}{ Sample } & \multirow[b]{2}{*}{$\begin{array}{l}\text { Pu-240 } \\
\text { Mass } \\
\text { (g) }\end{array}$} & \multicolumn{7}{|c|}{ Source of Uncertainty } \\
\hline & & $\begin{array}{l}\text { Branching } \\
\text { ratio }\end{array}$ & $\begin{array}{l}{ }^{133} \mathrm{Xe} \\
\text { Yield }\end{array}$ & $\begin{array}{l}{ }^{135} \mathrm{Xe} \\
\text { Yield }\end{array}$ & $\begin{array}{l}{ }^{133} \mathbf{X e} \\
\text { Activity }\end{array}$ & $\begin{array}{l}{ }^{135} \mathrm{Xe} \\
\text { Activity }\end{array}$ & $\begin{array}{l}\text { Sample } \\
\text { Volume }\end{array}$ & Cumulative \\
\hline & & $3.64 \%$ & $12.03 \%$ & $0.75 \%$ & $11.46 \%$ & $0.94 \%$ & $3.19 \%$ & $35.80 \%$ \\
\hline $2-\mathrm{A}$ & 2.2979 & $-3.39 \%$ & $-9.77 \%$ & $\begin{array}{l}- \\
0.82 \%\end{array}$ & $-11.36 \%$ & $-0.83 \%$ & $-3.19 \%$ & $-26.43 \%$ \\
\hline & & $3.64 \%$ & $12.03 \%$ & $0.75 \%$ & $11.45 \%$ & $1.05 \%$ & $4.12 \%$ & $37.18 \%$ \\
\hline $2-B$ & 2.1157 & $-3.39 \%$ & $-9.77 \%$ & $\begin{array}{l}- \\
0.82 \%\end{array}$ & $-11.36 \%$ & $-0.92 \%$ & $-4.12 \%$ & $-27.20 \%$ \\
\hline
\end{tabular}

The cumulative yields of Xe were used in this evaluation. It is expected that taking independent yields of Xe with each isotopes parent nuclide into account will improved the methodology. In addition, the radiochemical transport of iodine, the parent element of radioactive xenon released during fission, should be assessed. Iodine is highly electronegative, and bonds readily with organic molecules. This makes its transport potentially challenging in the waste tank environment. The resulting localization of xenon production from the accumulation of iodine may lead to uncertainty in the hold-up time in the waste tank. 


\subsection{Field Sampling Considerations}

This series of experiments has produced several useful lessons-learned on how to effectively sample gas to quantify ${ }^{240} \mathrm{Pu}$ via radioxenon measurements on a SAUNA-II system. There are several steps that can be taken to maximize the effectiveness of the waste tank sampling process and a few minor changes are required to the SAUNA II system to accurately quantify the radioxenon.

Waste tanks are sampled by compressing air from the tank headspace into gas cylinders for transport to the SAUNA-II. Acquiring a sufficient quantity of sample builds confidence in the final analysis of the ${ }^{240} \mathrm{Pu}$ mass; the SAUNA can process up to $15 \mathrm{~m}^{3}$ of air per measurement cycle and can make several measurements in a row. Taking several cycles worth of air samples from the tank allows this method to take maximum advantage of the SAUNA-II's capabilities and allows for vetting of the sample's consistency. From this research, it is recommended to acquire enough sample gas to support three consecutive measurement cycles. Understanding the tank's headspace air dynamics is also extremely useful when analyzing results. At minimum, an estimate of the total sample headspace volume is needed to quantify the ${ }^{240} \mathrm{Pu}$ in the waste tank. As mentioned in Section 4.1, the air flow rate of the headspace can impact the total xenon activity and the isotopic ratios, so measurements of the tank air flow rate are strongly recommended. Radon is another noble gas present in large quantities in waste tanks; it is likely that useful information could be determined via incorporation of radon monitoring of the tanks or of the samples. Further research on the utility of radon sampling for ${ }^{240} \mathrm{Pu}$ quantification is needed to see if it can be used to help determine variables such as noble gas hold-up, air flow, headspace volume, or to distinguish between different potential spontaneous fission sources.

Introducing the sample into the SAUNA-II in a quantifiable, repeatable way requires a minor modification to the SAUNA-II and some additional, external infrastructure. A specialized 3-way valve needs to be added to the SAUNA-II sampling path as described in more detail in Section 3.1. Some external plumbing needs to be added to connect this inlet valve with the sample bottles. This plumbing needs to have appropriate flow regulation and safety features to handle the typical flow rate of the SAUNA-II and the pressure of the sample gas cylinders. A typical gas cylinder will not hold enough sample gas to support a full SAUNA-II collection cycle, so a small gas manifold is needed to connect multiple gas cylinders together. Some supporting framework is needed to secure the sample gas cylinders. With these changes and additions, an experimenter can reliably quantify and control sample introduced into the SAUNA-II, and also smoothly transition between normal SAUNA-II operations and experimental sample injection. It should be noted however, that it is advisable to transport the compressed gas sample bottles to the SAUNAII system as quickly as possible. This speed is required to minimize decay of short lived xenon isotopes (such as Xe-135). 


\subsection{Conclusions}

Measurements of radioxenon were taken in the headspace air from a waste tank at the Hanford site in Washington State known to hold ${ }^{240} \mathrm{Pu}$ and other transuranic isotopes. In addition, a controlled experiment with a well-known mass of ${ }^{240} \mathrm{Pu}$ in a glove box was also performed. Following numerous iterations in the sampling procedure, the application of this method for ${ }^{240} \mathrm{Pu}$ mass verification is promising.

From previous measurements, it is believed that the ${ }^{240} \mathrm{Pu}$ in the mixed waste dominates the spontaneous fission in the tank, so it is possible to calculate the mass of ${ }^{240} \mathrm{Pu}$, after correcting for a number of others effects. The results reported are more than $50 \%$ lower than the best-estimate inventory of ${ }^{240} \mathrm{Pu}$ mass determined from measurements of samples taken from the tank, though considering the significant uncertainty in both the best-estimate inventory and effects of passive venting of headspace air, the calculated mass is comparable to the expected value. Additionally, in a more controlled, benchtop environment with a refined sampling method and a more accurately quantified ${ }^{240} \mathrm{Pu}$ mass, the resulting ${ }^{240} \mathrm{Pu}$ mass was determined to be $2.21{ }_{-0.59}^{+0.81} \mathrm{~g}$, which is in excellent agreement with the assayed mass of $2.39 \mathrm{~g}$.

This proof-of-principle demonstration using ultra-sensitive radio-xenon gas measurements to determine ${ }^{240} \mathrm{Pu}$ inventory of a waste tank shows great promise; however, more tests are necessary in order to minimize uncertainties in the process and scrutinize discrepancies seen in the measurements. In addition, the lack of reliable spontaneous fission product yields of ${ }^{240} \mathrm{Pu}$ the sensitivities precludes any significant reduction in this method's uncertainties.

Controlled sampling experiments with a well-known ${ }^{240} \mathrm{Pu}$ mass in a glove box gave much improved results compared to the early waste tank proof-of-concept experiment. This series of experiments on a well-understood sample allowed further refinement to sampling methodologies and calculation methods. This series of experiments demonstrates that when the sampling conditions are well-known, it is possible to get an excellent estimation of total ${ }^{240} \mathrm{Pu}$ mass via this methodology. 


\subsection{References}

[1] P. Dresel and S. Waichler, "Evaluation of Xenon Gas Detection as a Means for Identifying Buried Transuranic Waste at the Radioactive Waste Management Complex, Idaho National Environmental and Engineering Laboratory," Pacific Northwest National Laboratory, Richland, WA, PNNL-14617, 2004.

[2] M. W. Cooper et al., "Redesigned $\beta-\gamma$ radioxenon detector," Nuclear Instruments and Methods in Physics Research Section A: Accelerators, Spectrometers, Detectors and Associated Equipment, vol. 579, no. 1, pp. 426-430, Aug. 2007.

[3] N. E. Holden and D. C. Hoffman, "Spontaneous fission half-lives for ground-state nuclide (Technical report)," Pure and Applied Chemistry, vol. 72, no. 8, pp. 1525-1562, 2009.

[4] NNDC (National Nuclear Data Center), Interactive Chart of the Nuclides. (http://www.nndc.bnl.gov/chart/), 2015.

[5] G. F. Knoll, Radiation Detection and Measurement, 4 edition. Hoboken, NJ: Wiley, 2010.

[6] J. P. Lestone, "Energy Dependence of Plutonium Fission-Product Yields," Nuclear Data Sheets, vol. 112, no. 12, pp. 3120-3134, Dec. 2011.

[7] J. Lestone, "Personal Correspondance," 2013.

[8] K. Olsen, D. Mendoza, V. Woods, and D. Haas, "Using Radioxenon Gas Sampling and Analysis Methods to Estimate Total Plutonium Content Within Facilities on the Hanford Site.," Pacific Northwest National Laboratory, Richland, WA, PNNL-21992, 2012.

[9] A. Ringbom, T. Larson, A. Axelsson, K. Elmgren, and C. Johansson, "SAUNA — a system for automatic sampling, processing, and analysis of radioactive xenon," Nuclear Instruments and Methods in Physics Research Section A: Accelerators, Spectrometers, Detectors and Associated Equipment, vol. 508, no. 3, pp. 542-553, Aug. 2003.

[10] M. Adams, "Engineering Change Notice," Hanford, WA, Tank 241-TX-118, ECN 647951, May 2000.

[11] M. Schoeppner, "Performance Assessment of the CTBTO Noble Gas Network to Detect Nuclear Explosions," Pure Appl. Geophys., vol. 174, no. 5, pp. 2161-2171, May 2017.

[12] J. Huckaby, C. Evans, K. Olsen, Z. Antoniak, J. Julya, and D. Sklarew, "He and SF6 as tracers for determining ventilation rates of high-level radioactive waste tanks," Nuclear Energy, vol. 38, no. 2, pp. 99-105, 1999.

[13] P. L. Reeder, D. C. Stromswold, R. L. Brodzinski, J. H. Reeves, and W. E. Wilson, "Moisture measurement for radioactive wastes using neutron activation of copper," Applied Radiation and Isotopes, vol. 48, no. 2, pp. 247-256, Feb. 1997. 



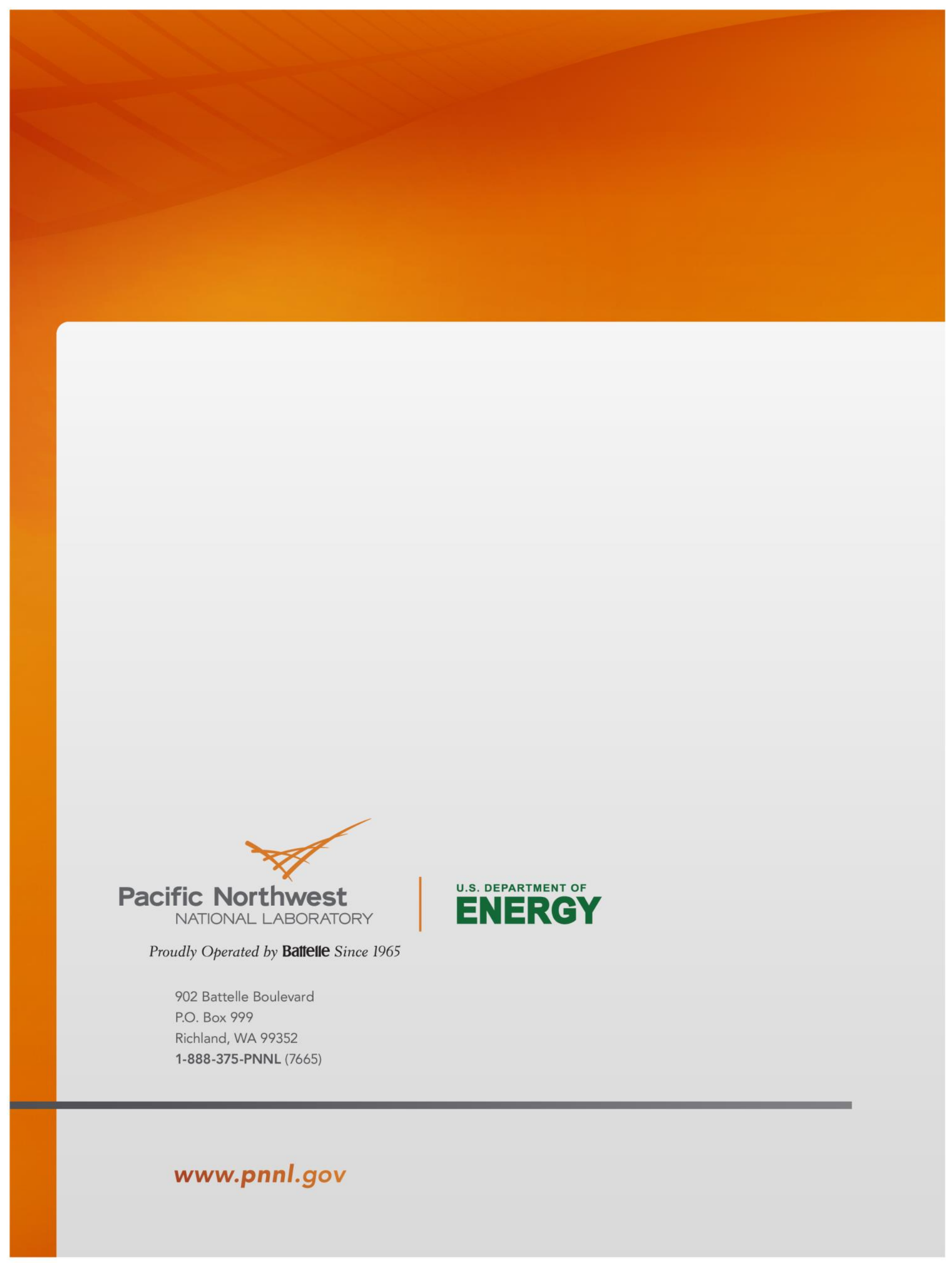

